\title{
Review \\ Recent advances in systemic therapy Advances in adjuvant systemic chemotherapy of early breast cancer
}

\author{
Sara López-Tarruella and Miguel Martín \\ Medical Oncology Department, Clínico San Carlos Hospital, Madrid, Profesor Martín Lagos, 28040 Madrid, Spain
}

Corresponding author: Miguel Martín, mmartin@geicam.org

Published: 19 March 2009

This article is online at http://breast-cancer-research.com/content/11/2/204

(c) 2009 BioMed Central Ltd
Breast Cancer Research 2009, 11:204 (doi:10.1186/bcr2226)

survival benefits from adjuvant therapy, with estimated reductions in the annual odds of death ranging from $8 \%$ to $28 \%$. These benefits are maintained in patients outside the controlled conditions of clinical trials and have contributed, alongside screening programs, to an overall reduction in breast cancer mortality between 1975 and 2000 [2].

During the late 1960s the earliest clinical trials in the field began to evaluate the biologic concept of adjuvant chemotherapy in node-positive breast cancer, determining the effects of various chemotherapy regimens compared to observation after surgery to remove the primary tumor [3]. These trials clearly demonstrated benefit from adjuvant chemotherapy in the subgroup of patients at high risk for recurrence $[4,5]$. Chemotherapy combinations including cyclophosphamide, methotrexate, and 5-fluorouracil (CMF) have exhibited longterm effectiveness in women with node-positive breast cancer [6]. CMF-like regimens were able to reduce the annual odds of recurrence and death in operable breast cancer patients by $24 \%( \pm 3 \%)$ and $14 \%( \pm 4 \%)$, respectively [7].

Subsequently, during the late 1970s and early 1980s, anthracycline-containing combinations were tested in prospective randomized adjuvant trials. Overall, the anthracycline regimens (5-fluorouracil, doxorubicin, and cyclophosphamide [FAC]; 5-fluorouracil, epirubicin, and cyclophosphamide [FEC]; and doxorubicin and cyclophosphamide [AC], among others) are associated with reductions in the risk for recurrence of $11.2 \%(2 P<0.0001)$ and in the risk for death of $16 \%$ $(2 P<0.00001)$, compared with CMF. Therefore, in absolute

$A C=$ doxorubicin and cyclophosphamide; $A D=$ doxorubicin and docetaxel; BCIRG = Breast Cancer International Research Group; CALGB = Cancer and Leukemia Group B; CEF = cyclophosphamide, epirubicin, and 5-fluorouracil; CMF = cyclophosphamide, methotrexate, and 5-fluorouracil; DFS = disease-free survival; EC = epirubicin and cyclophosphamide; ER = estrogen receptor; FAC = 5-fluorouracil, doxorubicin, and cyclophosphamide; FEC = 5-fluorouracil, epirubicin, and cyclophosphamide; GEICAM = Grupo Español para la Investigación del Cáncer de Mama; $\mathrm{HER}=$ human epidermal growth factor receptor; HR = hazard ratio; NSABP = National Surgical Adjuvant Breast and Bowel Project; OS = overall survival; RR = relative risk; TAC $=$ docetaxel, doxorubicin, and cyclophosphamide; TC $=$ docetaxel and cyclophosphamide; THC $=$ docetaxel, carboplatin, and trastuzumab; USO = US Oncology Network. 
terms, the benefit is about $3 \%$ at 5 years and $4 \%$ at 10 years $[8,9]$. The National Surgical Adjuvant Breast and Bowel Project (NSABP) group explored the differences between anthracycline and CMF regimens in two clinical trials, namely NSABP B-15 and B-23, showing that four cycles of AC were similar in terms of disease-free survival (DFS) and overall survival (OS) to six cycles of classical CMF $[10,11]$. Other randomized studies and a meta-analysis clearly demonstrated that six cycles of an anthracycline-containing combination (FAC; FEC; cyclophosphamide, doxorubicin, and 5-fluorouracil; and cyclophosphamide, epirubicin, and 5-fluorouracil [CEF]) were superior to six cycles of CMF $[7,8,12]$. The optimal duration of the adjuvant therapy was also addressed in a French study (FASG-01) [13], which demonstrated that six cycles of adjuvant FEC were superior to three cycles of the same regimen in patients with operable breast cancer. Based on this growing body of evidence, during the 1990s consensus emerged that six cycles of a three-drug anthracycline-containing combination was the optimal adjuvant treatment for node-positive operable breast cancer, although the use of four-cycle $\mathrm{AC}$ and six-cycle $\mathrm{CMF}$ remained common practice in many institutions.

More recently, the taxanes have been added to the adjuvant armamentarium and are broadly used. In this review we address current prospects of adjuvant therapy, focusing on the advances in chemotherapy with taxanes and on treatment individualization; we also give attention to likely future developments involving taxanes intended to improve further outcomes in early-stage breast cancer.

\section{Taxanes as adjuvant therapy for breast cancer}

The taxanes paclitaxel and docetaxel have a partial lack of cross-resistance with anthracyclines and were established in the 1990s as part of the standard treatment for metastatic breast cancer. Testing of these agents in the adjuvant setting was therefore also begun at that time.

Several phase III clinical trials have evaluated taxanes in the adjuvant setting. There are two generations of taxane clinical trials. In first-generation trials, a taxane-containing combination was compared with an anthracycline, nontaxane combination. In the second generation of trials, initiated once the taxanes became regarded as the 'gold standard', taxanes were included in all comparator arms.

In the first-generation trials (Tables 1 and 2) taxanes were added to conventional adjuvant anthracycline regimens, and were given either sequentially after the anthracyclines or concurrently in combination with them.

\section{First-generation paclitaxel-containing regimens}

The trials discussed here are summarized in Table 1.

The first reported taxane study, the 9344-INT 08 trial [14], was conducted by the Cancer and Leukemia Group B
(CALGB). Conducted in pre- and postmenopausal women with node-positive breast cancer, the study aimed to determine whether the benefits of four cycles of conventional AC could be improved upon either by doxorubicin dose escalation or by adding paclitaxel. A $3 \times 2$ factorial design was used to address both questions in one trial. Patients were randomly assigned to receive doxorubicin at one of three different dosages $\left(60,75\right.$, or $\left.90 \mathrm{mg} / \mathrm{m}^{2}\right)$ in combination with a fixed dose of cyclophosphamide $\left(600 \mathrm{mg} / \mathrm{m}^{2}\right)$, and then to receive or not receive four courses of paclitaxel (175 mg/m² every 3 weeks). After a median follow up of 69 months, no significant reduction in relation to doxorubicin dose was identified in the hazard of recurrence or of death. However, the addition of paclitaxel to $\mathrm{AC}$ led to a $17 \%$ reduction in the risk for recurrence $(P=0.0023)$ and up to an $18 \%$ reduction in the risk for death $(P=0.0064)$. The main concern with these data is that the superiority of the taxanecontaining regimen could partly be attributed to the more protracted therapy in this arm (3 versus 6 months), as opposed to a direct effect of the taxane therapy.

With a very similar design, the NSABP B-28 trial [15] added four cycles of paclitaxel at a higher dose $\left(225 \mathrm{mg} / \mathrm{m}^{2}\right.$ every 3 weeks) to four cycles of $A C\left(60 / 600 \mathrm{mg} / \mathrm{m}^{2}\right)$ in a sequential schedule, and administered adjuvant tamoxifen to all hormone receptor-positive patients and those older than 50 years, concurrent with chemotherapy. The addition of paclitaxel conferred a reduction in the risk for recurrence of $17 \%$ $(P=0.006)$ over that in patients treated with four cycles of AC. Analysis of OS, however, did not reveal any statistically significant differences between arms.

On the European side, the Grupo Español para la Investigación del Cáncer de Mama (GEICAM) recently reported the results of the 9906 trial [16], which had a median follow-up period of 66 months. Patients with nodepositive operable breast cancer were randomized after surgery to receive six cycles of FEC (fluorouracil $600 \mathrm{mg} / \mathrm{m}^{2}$, epirubicin $90 \mathrm{mg} / \mathrm{m}^{2}$, and cyclophosphamide $600 \mathrm{mg} / \mathrm{m}^{2}$ on day 1 every 3 weeks) or four cycles of the same FEC regimen followed by 8 weeks of administration of paclitaxel $\left(100 \mathrm{mg} / \mathrm{m}^{2}\right.$ per week). Therefore, the duration of adjuvant treatment in both arms was very similar. After adjustment for other variables, FEC plus paclitaxel significantly reduced the risk for relapse by $23 \%$ compared with FEC, and the difference in DFS between the two arms was related to the greater number of distant breast cancer relapses in the FEC group. The analysis of OS identified a trend in favor of the paclitaxel arm, but the difference was not statistically significant at this point in the follow up $(P=0.109)$.

The Hellenic Cooperative Oncology Group trial HE 10/97 [17] compared three cycles of epirubicin $\left(110 \mathrm{mg} / \mathrm{m}^{2}\right)$ followed by three cycles of paclitaxel $\left(250 \mathrm{mg} / \mathrm{m}^{2}\right)$ and three cycles of intensified CMF (cyclophosphamide $840 \mathrm{mg} / \mathrm{m}^{2}$, methotrexate $57 \mathrm{mg} / \mathrm{m}^{2}$, and 5 -fluorouracil $840 \mathrm{mg} / \mathrm{m}^{2}$ ) versus 


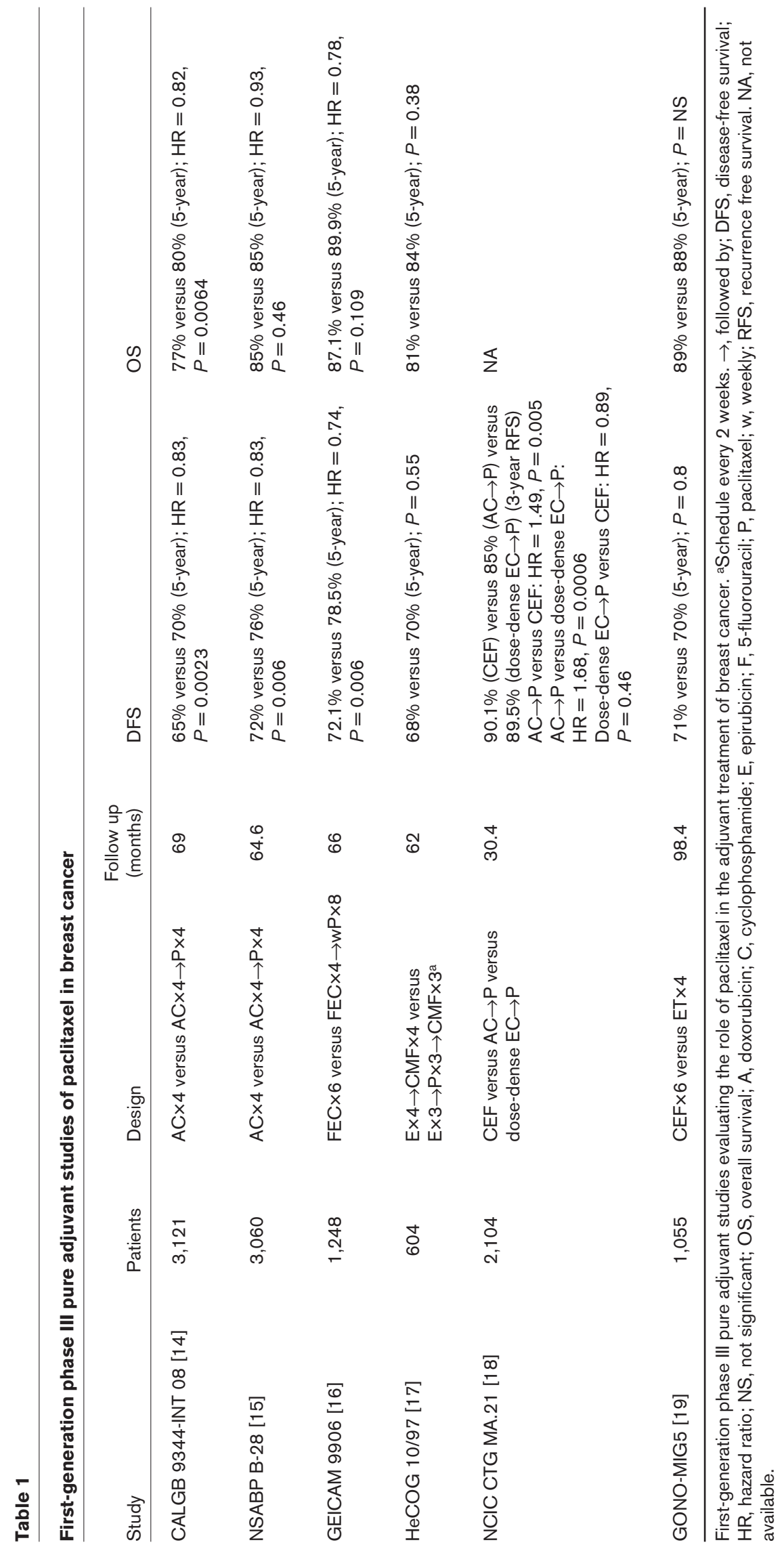




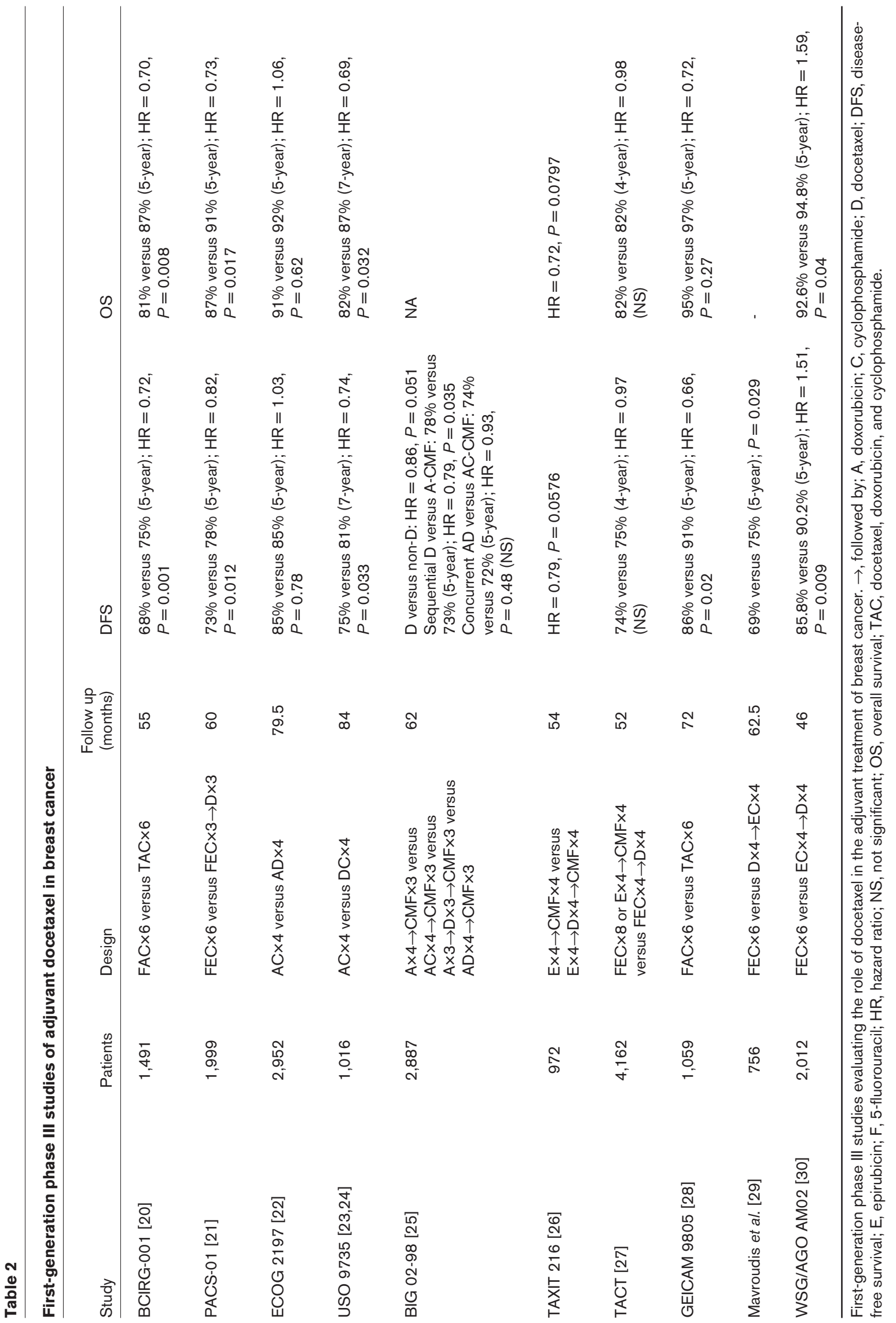


four cycles of epirubicin every 2 weeks followed by four cycles of intensified CMF. The study identified a trend toward better survival in the taxane-containing arms, albeit without statistical significance. However, the study was underpowered to show small but clinically relevant differences.

More recently other two clinical trials have been reported in abstract form. The National Cancer Institute of Canada Clinical Trials Group MA.21 study, reported by Burnell and coworkers [18], tested the hypothesis that the addition of 3 months of paclitaxel after dose-dense epirubicin and cyclophosphamide (EC) chemotherapy would be superior to CEF alone or AC followed by paclitaxel. AC followed by paclitaxel, although less toxic, was inferior to the other arms in terms of recurrence-free survival, but it was still too early to detect any differences between CEF and dose-dense EC plus paclitaxel.

The most recently presented trial is a phase III study conducted by the Gruppo Oncologico Nord Ovest and Mammella Intergruppo, namely the GONO-MIG-5 study [19]. The study compared CEF (cyclophosphamide $600 \mathrm{mg} / \mathrm{m}^{2}$, epirubicin $60 \mathrm{mg} / \mathrm{m}^{2}$, and 5 -fluorouracil $600 \mathrm{mg} / \mathrm{m}^{2}$ given every 3 weeks for six cycles) versus EP (epirubicin $90 \mathrm{mg} / \mathrm{m}^{2}$ and paclitaxel $175 \mathrm{mg} / \mathrm{m}^{2}$ 3-hour infusion given every 3 weeks for four cycles). No significant differences in DFS or OS were observed.

\section{First-generation docetaxel-containing regimens}

The trials discussed here are summarized in Table 2.

Chronologically, the first report of docetaxel administered concurrently with anthracyclines comes from the Breast Cancer International Research Group (BCIRG)-001, in the form of their TAX316 trial [20]. This study randomly assigned women with node-positive breast cancer to six cycles of TAC (docetaxel $75 \mathrm{mg} / \mathrm{m}^{2}$, doxorubicin $50 \mathrm{mg} / \mathrm{m}^{2}$, and cyclophosphamide $500 \mathrm{mg} / \mathrm{m}^{2}$ ) or FAC (fluorouracil $500 \mathrm{mg} / \mathrm{m}^{2}$, doxorubicin $50 \mathrm{mg} / \mathrm{m}^{2}$, and cyclophosphamide $500 \mathrm{mg} / \mathrm{m}^{2}$ ) every 3 weeks. TAC was associated with a statistically significant reduction in the risk for relapse and death $(28 \%$ and $30 \%$, respectively) relative to FAC. The reduction in the risk for relapse did not appear to be driven by nodal status or by hormone receptor or human epidermal growth factor receptor (HER)2 status. In terms of toxicity, febrile neutropenia and asthenia were the main side effects of TAC.

Shortly after the BCIRG-001 trial was reported, another French study, the Federation Nationale des Centres de Lutte Contre le Cancer PACS-01 trial [21], noted similar results supporting the use of sequential docetaxel in early breast cancer. Node-positive breast cancer patients were assigned to receive FEC (fluorouracil $500 \mathrm{mg} / \mathrm{m}^{2}$, epirubicin $100 \mathrm{mg} / \mathrm{m}^{2}$, and cyclophosphamide $500 \mathrm{mg} / \mathrm{m}^{2}$ ) for six cycles or the same regimen of FEC for three cycles followed by docetaxel $100 \mathrm{mg} / \mathrm{m}^{2}$ every 3 weeks for another three cycles. The multivariate analysis adjusting for prognostic factors identified a statistically significant reduction in the relative risk for relapse with FEC plus docetaxel (18\%). There was a statistically significant reduction in risk for death as well (27\%).

The Eastern Cooperative Oncology Group 2197 trial [22] randomized both node-positive and high-risk node-negative breast cancer patients to receive four cycles of $A C$ or four cycles of $A D$ (doxorubicin $60 \mathrm{mg} / \mathrm{m}^{2}$ plus docetaxel $60 \mathrm{mg} / \mathrm{m}^{2}$ ). Recently communicated results, with a median of 79.5 months of follow up, revealed no differences in DFS or OS. These negative results suggest either that the low dose of docetaxel used in the combination $\left(60 \mathrm{mg} / \mathrm{m}^{2}\right)$ or that the concurrent administration in a short course of $A C$ are not the most effective ways to use docetaxel in the adjuvant setting.

The US Oncology Network (USO) 9735 trial [23,24] is unique because it compared four cycles of $A C$ versus four cycles of a taxane-containing, non-anthracycline regimen (docetaxel $75 \mathrm{mg} / \mathrm{m}^{2}$ plus cyclophosphamide $600 \mathrm{mg} / \mathrm{m}^{2}$ [TC]). Both node-positive and node-negative patients were included in the trial. Both DFS and OS were statistically significantly improved with TC. However, TC produced more myalgia, arthralgia, edema and febrile neutropenia, whereas more nausea and vomiting as well as one incident of congestive heart failure were the main secondary effects in the $\mathrm{AC}$ arm. In addition, TC was well tolerated in older women, without excessive toxicity in comparison with their younger counterparts.

The Breast International Group 02-98 trial [25] compared four treatment arms: a sequential control (four cycles of doxorubicin at $75 \mathrm{mg} / \mathrm{m}^{2}$, followed by three cycles of CMF); a concurrent control arm (four cycles of doxorubicin at $60 \mathrm{mg} / \mathrm{m}^{2}$ plus cyclophosphamide at $600 \mathrm{mg} / \mathrm{m}^{2}$, followed by three cycles of CMF); a sequential docetaxel arm (three cycles of doxorubicin at $75 \mathrm{mg} / \mathrm{m}^{2}$, followed by three cycles of docetaxel at $100 \mathrm{mg} / \mathrm{m}^{2}$, followed by three cycles of CMF); and a concurrent docetaxel arm (four cycles of doxorubicin at $50 \mathrm{mg} / \mathrm{m}^{2}$ plus docetaxel at $75 \mathrm{mg} / \mathrm{m}^{2}$ followed by three cycles of CMF). The analysis was performed after a median follow up of at least 5 years but with less than two-thirds of the number of DFS events originally planned, which limited the statistical power to answer definitively the originally planned questions. The primary comparison evaluated the incorporation of docetaxel, regardless of its schedule of administration, into anthracycline-based adjuvant chemotherapy, and it resulted in improved DFS of borderline statistical significance (hazard ratio [HR] of a DFS event of 0.86). Secondary comparisons found differences in efficacy possibly related to schedule of administration of chemotherapy. Thus, DFS was significantly better in the sequential docetaxel arm than in the sequential control arm (HR of a DFS event was 0.79), but DFS was no different in the concurrent docetaxel arm and in the concurrent control (HR of a DFS event was 0.93). When the two docetaxel arms were compared, DFS was better in the sequential docetaxel arm (HR of a DFS event was 0.83). 
In the TAXIT 216 trial [26], node-positive breast cancer patients were randomly assigned either to epirubicin $\left(120 \mathrm{mg} / \mathrm{m}^{2}\right)$ for four cycles followed by CMF for four cycles (considered the standard treatment in Italy during the late 1990s) or to sequential docetaxel $\left(100 \mathrm{mg} / \mathrm{m}^{2}\right)$ for four cycles after four cycles of epirubicin and before four cycles of CMF. With a median follow-up period of 53.6 months, there was a tendency toward a benefit for the docetaxel-containing arm in terms of DFS (21\% reduction in the risk for relapse, which was of borderline statistical significance).

The Taxotere as Adjuvant Chemotherapy trial [27] is the largest first-generation taxane-based adjuvant trial conducted to date. It compared four cycles of $\mathrm{FE}_{60} \mathrm{C}$ (fluorouracil $600 \mathrm{mg} / \mathrm{m}^{2}$, epirubicin $60 \mathrm{mg} / \mathrm{m}^{2}$, and cyclophosphamide $600 \mathrm{mg} / \mathrm{m}^{2}$ every 3 weeks) followed by four cycles of docetaxel $\left(100 \mathrm{mg} / \mathrm{m}^{2}\right)$ versus a standard treatment (either eight cycles of $\mathrm{FE}_{60} \mathrm{C}$ or four cycles of epirubicin $100 \mathrm{mg} / \mathrm{m}^{2}$ followed by four cycles of CMF, at investigators' discretion). No differences in DFS or OS between experimental and standard arms were observed.

The Taxotere as Adjuvant Chemotherapy trial included both node-positive and high-risk node-negative patients, but the GEICAM 9805 trial [28] is the first taxane-based study that exclusively enrolled women with node-negative early-stage breast cancer at high risk for recurrence. As a complementary study to that conducted by BCIRG 001, GEICAM 9805 tested the same treatment arms but in a different population. TAC produced significantly more hematologic toxicity than did FAC, although primary prophylaxis with granulocyte colony-stimulating factor reduced the rate of neutropenic fever. A significant improvement in 5-year DFS was demonstrated in the TAC over the FAC arm, with $91 \%$ and $86 \%$ patients, respectively, alive and disease free. The OS data, although still immature, showed a nonsignificant 5-year OS of 97\% for TAC and $95 \%$ for FAC.

Mavroudis and coworkers [29], from the Hellenic Oncology Research Group, presented data from another phase III study that compared the sequential administration of docetaxel (four cycles of $100 \mathrm{mg} / \mathrm{m}^{2}$ ) followed by $E C$ versus $\mathrm{FE}_{75} \mathrm{C}$ (fluorouracil $700 \mathrm{mg} / \mathrm{m}^{2}$, epirubicin $75 \mathrm{mg} / \mathrm{m}^{2}$, and cyclophosphamide $700 \mathrm{mg} / \mathrm{m}^{2}$ every 3 weeks) as adjuvant chemotherapy in node-positive breast cancer. The docetaxel-containing treatment significantly improved the recurrence-free survival, but it was more toxic than FEC. The West German Study Group has also reported the results of the randomized intergroup phase III trial comparing EC followed by docetaxel versus $\mathrm{FE}_{100} \mathrm{C}$ (fluorouracil $500 \mathrm{mg} / \mathrm{m}^{2}$, epirubicin $100 \mathrm{mg} / \mathrm{m}^{2}$, and cyclophosphamide $500 \mathrm{mg} / \mathrm{m}^{2}$ every 3 weeks) in patients with intermediate-risk breast cancer. The 5-year OS rate was significantly higher with EC followed by docetaxel (95\%) than for FEC (92.6\%), suggesting the consideration of the sequential regimen in patients with one to three involved lymph nodes, even in hormone receptor-positive disease [30].

\section{Second-generation taxane trials}

Once the results of the first-generation taxane trials became available, taxanes were adopted as the new standard adjuvant treatment for node-positive breast cancer. Therefore, a second generation of trials was planned to define further the best taxane, the optimal schedule of administration, and whether the addition of further agents might be of some benefit. The trials discussed here are summarized in Table 3.

The earliest of these second-generation trials was the CALBG 9741 trial [31]. It was designed to test two hypotheses: the first was that dose-dense administration of chemotherapy was superior to conventional, every 3 weeks administration; and the second was that sequential, full-drug dosage was superior to combination chemotherapy. Nodepositive breast cancer patients were assigned to one of the four possible treatment arms, consisting of sequential chemotherapy using doxorubicin, cyclophosphamide and paclitaxel, or concurrent doxorubicin and cyclophosphamide followed by paclitaxel at 14-day (with growth factor support) versus 21day intervals in a $2 \times 2$ factorial design. Dose-dense chemotherapy was superior to conventional scheduling, but there was no significant difference between sequential and concurrent administration schedules. These data were consistent with one of the underlying hypotheses (namely that dose density could increase efficacy with a reasonable toxicity profile) but not the other (that sequential, full-dose therapy is superior to combination chemotherapy).

Other second-generation initiatives helped to shed light on the best taxane and the best schedule of administration of taxanes as well. The Southwest Oncology Group/Eastern Cooperative Oncology Group E1199 trial [32] included 4,950 nodepositive or high-risk node-negative early breast cancer patients and randomly assigned them to one of the four treatment arms in a factorial design. All patients received AC for four cycles followed by taxane treatment, either docetaxel or paclitaxel, for 12 weeks in a weekly schedule $\left(80 \mathrm{mg} / \mathrm{m}^{2}\right.$ paclitaxel and $35 \mathrm{mg} / \mathrm{m}^{2}$ docetaxel) or every 3 weeks for four cycles (175 mg/m² paclitaxel and $100 \mathrm{mg} / \mathrm{m}^{2}$ docetaxel). The primary end-points of the study were docetaxel versus paclitaxel efficacy and weekly versus every 3 weeks schedule. No significant differences in efficacy were found in the primary analysis (paclitaxel versus docetaxel, and weekly versus every 3 weeks schedule). This appears to have been due to the fact that paclitaxel performed better weekly, whereas docetaxel was more efficacious when administered every 3 weeks. As a secondary analysis, there was significantly better DFS in the group receiving weekly paclitaxel and in the group receiving docetaxel every 3 weeks, as compared with the group receiving paclitaxel every 3 weeks (considered as standard).

Besides the last two trials discussed above, the results from the Cancer Research UK tAnGo phase III study [33] were recently presented. This is the first trial to test whether the addition of further chemotherapy agents to anthracycline and 


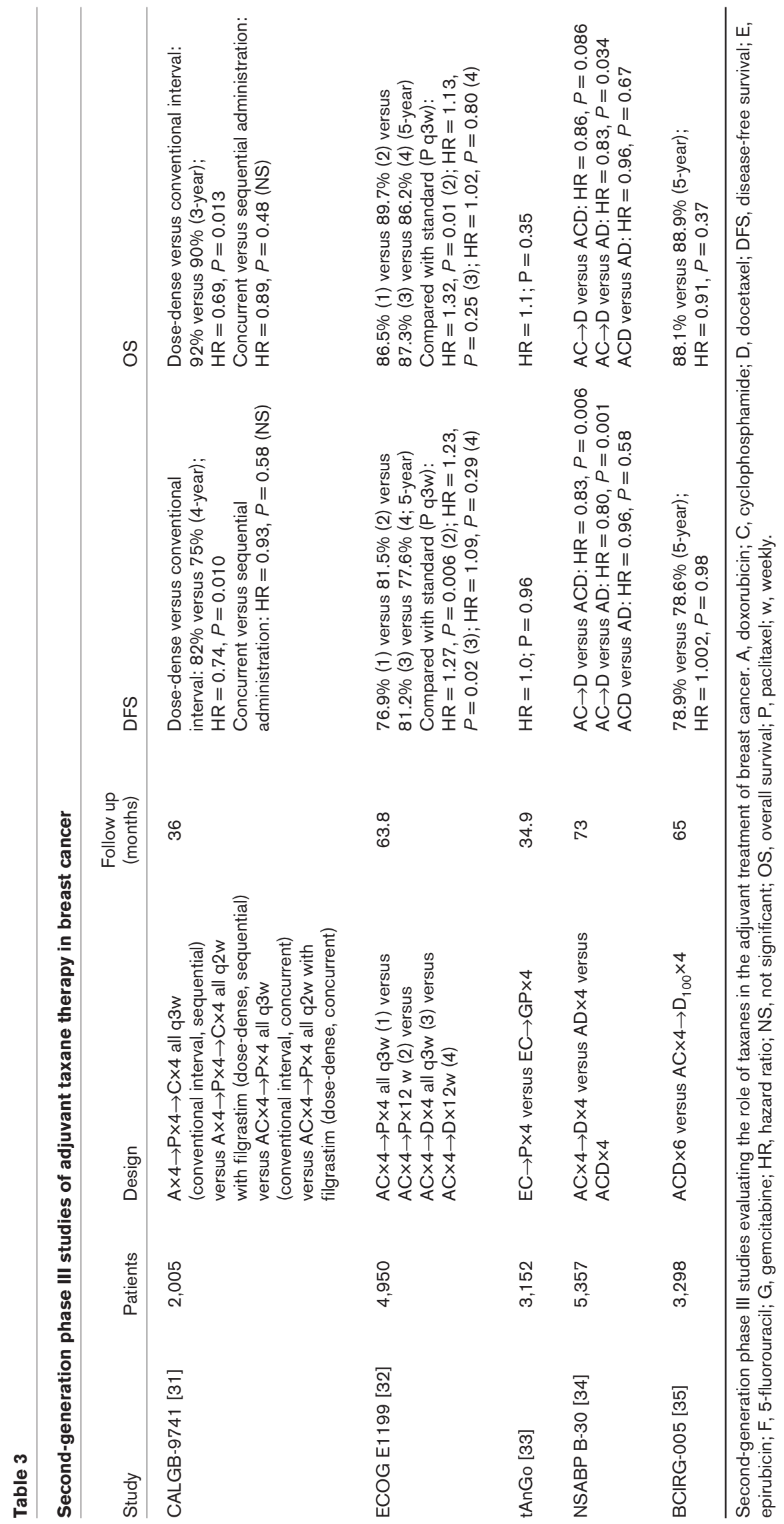


taxane-containing regimens could be useful in the adjuvant setting. tAnGo compared EC-GP (four cycles of epirubicin $90 \mathrm{mg} / \mathrm{m}^{2}$ and cyclophosphamide $600 \mathrm{mg} / \mathrm{m}^{2}$ every 3 weeks, followed by four cycles of paclitaxel $175 \mathrm{mg} / \mathrm{m}^{2}$ on day 1 and gemcitabine $1,250 \mathrm{mg} / \mathrm{m}^{2}$ on days 1 and 8 every 3 weeks) versus four cycles of EC followed by four cycles of paclitaxel $175 \mathrm{mg} / \mathrm{m}^{2}$. No significant differences in DFS or OS were observed between treatments.

At the 31st San Antonio Breast Cancer Symposium, data on two clinical trials exploring different combinations of taxanes were also reported. The NSABP B-30 [34] compared three different regimens containing doxorubicin, docetaxel, and cyclophosphamide in women with operable, node-positive breast cancer (four cycles of $A C$ followed by four cycles of docetaxel; four cycles of $A D$; and four cycles of $T A C$ ). According to the primary end-point, $A C$ followed by docetaxel was marginally superior to four cycles of $\mathrm{TAC}(\mathrm{HR}=0.86$; $P=0.086)$ and superior to four cycles of $A D(H R=0.83$; $P=0.034)$ in terms of OS. Also, AC followed by docetaxel was superior to four cycles of TAC (HR $=0.83 ; P=0.006)$ and of $\mathrm{AD}(\mathrm{HR}=0.80 ; P=0.001)$ in terms of DFS. Furthermore, there were no treatment interactions between baseline nodal, estrogen receptor (ER), or menopausal status and outcome. The main efficacy analysis of BCIRG 005 [35] was also presented. This phase III randomized trial compared TAC versus $A C$ followed by docetaxel in women with normal HER2 and axillary lymph node-positive early breast cancer. In terms of the primary end-point, namely DFS, adjuvant TAC was equivalent to $\mathrm{AC}$ followed by docetaxel, despite the higher dose intensity of each of the three agents in the latter regimen and the eight cycles of treatment. From the toxicity standpoint, TAC was associated with more febrile neutropenia and granulocyte colony-stimulating factor use and less sensory neuropathy, nail change, and myalgia.

Interesting data from other taxane clinical trials are about to be released (Table 4), and they are expected to provide information on many unresolved issues in the field of taxane chemotherapy, such as the following: the optimal administration schedule and the optimal combination regimen (NSABP B-38, USO 01062 and 11271, CALBG-40101, Southwest Oncology Group 0221, GEICAM 2003-02 or CT/01-04); the best taxane (NSABP B-38 and CT/04.22); and the benefits of combination with other agents in the adjuvant setting (NO17629, GEICAM 2003-10, and NSABP $B-38)$. Another major objective is to define the role of anthracyclines in the adjuvant treatment of HER2-negative patients. The USO Network 06090 trial is intended to address this by comparing the TC and TAC regimens in more than 2,000 early-stage breast cancer patients.

\section{Systematic reviews and meta-analysis of taxanes}

The magnitude of the benefit from including taxanes in the adjuvant treatment of early breast cancer has been investigated in several meta-analyses.
A pooled analysis including 15,500 patients, from nine trials [14,15,17,20,21,23,36-38], was reported by Bria and coworkers [39]. Significant differences in favor of taxanes were seen in DFS in the overall population (relative risk $[R R]=$ 0.86, $P<0.00001)$ and lymph node-positive population (RR $=0.84, P<0.0001)$, and in OS in both populations (RR $=0.87, P<0.0001$, and $\mathrm{RR}=0.84, P<0.0001$, respectively). The absolute benefits in DFS and OS in favor of taxanes ranged from $3.3 \%$ to $4.6 \%$ and from $2.0 \%$ to $2.8 \%$, respectively. Even restricting the analysis to the lymph nodepositive patients, the absolute gains in DFS and OS were $4.3 \%$ and $2.8 \%$, and the benefit was observed regardless of whether the sequential or concomitant approach was investigated. The number of patients needed to treat for a single beneficial patient ranged from 23 to 31 for DFS and from 36 to 50 for OS.

Subsequently, and with more mature survival data available, the Cochrane Collaboration [40] selected 12 studies [14-17, $20,21,23,25,26,37,38,41]$, including more than 18,000 women and a median follow-up of 60.4 months. The HR was $0.81(P<0.00001)$ both for DFS and OS favoring taxane regimens, with no statistical heterogeneity for either survival end-point. This review was not able to identify a subgroup of patients who benefit more or less from taxanes, and no conclusions were drawn with respect to dosage and scheduling.

Taxane-containing adjuvant trials were included in the most recent, 2005 to 2006 updated version of the Early Breast Cancer Trialists' Collaborative Group overview presented by Peto [9]. The recurrence rate ratio of taxane versus anthracycline in 20,000 randomized women was 0.83 $(2 P<0.00001)$. Stratifying women by age, in young women the recurrence rate ratio of taxane versus no taxane was $0.38(2 P<0.00001)$ and the breast cancer mortality rate ratio was $0.46(2 P<0.00001)$, whereas in older women the proportional risk reduction was $0.52(2 P<0.00001)$ in terms of recurrence rate and $0.66(P=0.00002)$ in terms of mortality. These data emphasize the role played by taxanes as new drugs to be included in the adjuvant treatment strategy of early breast cancer.

The largest meta-analysis reported thus far is that conducted by De Laurentiis and coworkers [42]. It included 13 studies $[14-17,20,21,25,26,36-38,43,44]$ and as many as 22,903 patients. The pooled HR estimated was $0.83(P<0.00001)$ for DFS and $0.85(P<0.00001)$ for OS. Risk reduction was not influenced by the type of taxane (paclitaxel: $\mathrm{HR}=0.83$, $P=0.0004$; and docetaxel: $\mathrm{HR}=0.87, P=0.003$ ), by $\mathrm{ER}$ expression (ER-positive: $H R=0.83, P<0.00001$; and ERnegative: $H R=0.79 ; P<0.00001)$, by the number of axillary metastases (one to three nodes: $\mathrm{HR}=0.71, P<0.0001$; and four nodes or more: $\mathrm{HR}=0.75, P=0.0001$ ), or by age/ menopausal status. Taxane administration resulted in absolute improvements in 5-year DFS/OS of $5 \%$ and $3 \%$, 
Table 4

Overview of the main ongoing or closed but still not reported clinical trials that involve taxanes

\begin{tabular}{|c|c|c|}
\hline Trial ID & Design & Patient characteristics and end-points \\
\hline \multicolumn{3}{|c|}{ Trials not recruiting or completed } \\
\hline NO17629 & $\mathrm{AC} \times 4 \rightarrow \mathrm{D}_{100} \times 4$ versus $\mathrm{AC} \times 4 \rightarrow \mathrm{D}_{75} \mathrm{X} \times 4$ & 1,810 node-positive and high-risk node-negative patients \\
\hline NSABP B-38 & $\begin{array}{l}A C D \times 6 \text { versus } A C \times 4(q 2 w) \rightarrow P \times 4(q 2 w) \\
\text { versus } A C \times 4(q 2 w) \rightarrow P G \times 4(q 2 w)\end{array}$ & $\begin{array}{l}\text { 4,800 node-positive patients; DFS (primary); OS, recurrence and } \\
\text { distant recurrence-free interval and toxicity (secondary) }\end{array}$ \\
\hline СТ/04.22 & $\begin{array}{l}\text { FEC } \times 4(q 2 w) \rightarrow D \times 4(q 2 w) \text { versus } \\
\text { FEC } \times 4(q 2 w) \rightarrow P \times 4(q 2 w)\end{array}$ & $\begin{array}{l}478 \text { node-positive patients; DFS (primary); OS, recurrence rate, } \\
\text { toxicity and QoL (secondary) }\end{array}$ \\
\hline GEICAM 2003-10 & $\mathrm{EC} \times 4 \rightarrow \mathrm{D} \times 4$ versus $\mathrm{ED} \times 4 \rightarrow \mathrm{X} \times 4$ & $\begin{array}{l}1,382 \text { node-positive patients; DFS (primary); OS, toxicity, QoL, SNP } \\
\text { predictors and molecular markers (secondary) }\end{array}$ \\
\hline GEICAM 2003-02 & $\mathrm{FAC} \times 6$ versus $\mathrm{FAC} \times 4 \rightarrow \mathrm{P} \times 8 \mathrm{w}$ & $\begin{array}{l}\text { 1,920 high risk node-negative patients; DFS (primary); OS, toxicity, } \\
\text { QoL and prognostic gene profile (2) }\end{array}$ \\
\hline \multicolumn{3}{|c|}{ Trials actively recruiting } \\
\hline CALGB-40101 & $\begin{array}{l}A C \times 4(q 2 w) \text { versus } A C \times 6(q 2 w) \\
\text { versus } P \times 4(q 2 w) \text { versus } P \times 6(q 2 w)\end{array}$ & $\begin{array}{l}\text { 4,646 with } 0 \text { to } 3 \text { positive nodes patients; DFS (primary); OS, local } \\
\text { control, time to distant metastasis, toxicity, amenorrhea, MDR1 } \\
\text { haplotype effect, CYP polymorphism effect }\end{array}$ \\
\hline LMU-ADEBAR & $\begin{array}{l}\text { EF }(d 1, d 8) C(\text { oral } d 1-14) \times 6(q 4 w) \\
\text { versus } E C(d 1, d 21, d 42, d 63) \rightarrow D(d 84 \\
d 105, d 126,147)\end{array}$ & $\begin{array}{l}446 \text { node-positive patients; time to progression (primary); OS, toxicity } \\
\text { and QoL (secondary) }\end{array}$ \\
\hline SWOG-S0221 & $\begin{array}{l}A C \times 6(q 2 w) \rightarrow P \times 6(q 2 w) \text { versus } \\
A C \times 6(q 2 w) \rightarrow P \times 12(w) \text { versus } \\
A C \times 15(A w, C \text { oral } d 1-7) \rightarrow P \times 6(q 2 w) \\
\text { versus } A C \times 15(A w, C \text { oral } d 1-7) \rightarrow P \times 12(w)\end{array}$ & $\begin{array}{l}4,500 \text { node-positive and high-risk node-negative patients; DFS } \\
\text { (primary); OS, toxicity and prognostic markers (secondary) }\end{array}$ \\
\hline CT/01.04 & $\mathrm{D}_{75} \times 4 \rightarrow \mathrm{E}_{90} \times 4$ versus $\mathrm{E}_{75} \mathrm{D}_{75} \times 6$ & $\begin{array}{l}724 \text { high-risk node-negative patients; DF interval (primary); OS and } \\
\text { safety (secondary) }\end{array}$ \\
\hline USO 06090 & $\mathrm{TAC} \times 6$ versus $\mathrm{TC} \times 6$ & $\begin{array}{l}\text { HER2 negative and node-positive and high-risk node-negative patients; } \\
\text { DFS (primary) }\end{array}$ \\
\hline
\end{tabular}

Overview of the main ongoing or closed but still unreported clinical trials that involve taxanes in their design as early breast cancer adjuvant treatment. The first part of the table includes trials that are active but not recruiting or have already completed, and the second part of the table is composed of clinical trials with active recruitment on August 2008, according to the National Cancer Institute Clinical Trial Database [71]. A, doxorubicin; C, cyclophosphamide; D, docetaxel; DFS, disease-free survival; E, epirubicin; F, 5-fluorouracil; G, gemcitabine; OS, overall survival; P, paclitaxel; OoL, quality of life; w, weeks; X, capecitabine.

respectively, which is comparable to the reduction obtained with anthracyclines and reported in the Early Breast Cancer Trialists' Collaborative Group meta-analysis [8], which established taxanes' gold-standard status in the adjuvant setting.

\section{Selection of candidates for adjuvant chemotherapy}

The identification of patients who do not need or are unlikely to benefit from adjuvant chemotherapy is currently a relevant problem, because small, node-negative tumors are the usual form of presentation of the disease in the era of mammographic screening. Furthermore, there is also probably a relevant subset of patients with node-positive breast cancer (particularly those with high expression of ER) that does not benefit from any chemotherapy [45]. However, the lack of prospective validation of this concept in the setting of an appropriate clinical trial renders its clinical application difficult.
In node-negative patients, tumor size, hormone receptor status, lymphovascular invasion, and histologic and nuclear grade have traditionally been the discriminating factors for selecting node-negative breast cancer patients for adjuvant chemotherapy. Adjuvant! [46], a program that estimates a patient's risk for recurrence with different therapeutic options based on classical clinical and pathological findings, is often used for the same purpose [47]. Patients with a risk for relapse exceeding $10 \%$ (with or without hormonal therapy, depending on hormone receptor status) are often offered adjuvant chemotherapy. The St Gallen Consensus Conference [48] has also established successive classifications of risk for relapse based on clinical and pathologic features, including HER2 status in its last version. More recently, two genomic signatures, Oncotype $D x^{\circledR}$ (Genomic Health Inc., Redwood City, CA, USA) and Mammaprint ${ }^{\circledR}$ (Agendia BV, Amsterdam, The Netherlands), have been developed to select those patients with node-negative disease who are 
more likely to benefit from adjuvant chemotherapy. A detailed description of these tools is beyond the scope of this overview. Pending a final validation in the MINDACT (Microarray in Node Negative Disease May Avoid ChemoTherapy) and TAILORx (Trial Assigning Individualized Options for Treatment $[R x])$ trials $[49,50]$, the genomic fingerprints appear to predict recurrence in node-negative breast cancer patients (and perhaps in node-positive patients as well) more accurately than Adjuvant! or the classical prognostic factors.

\section{Selection of adjuvant chemotherapy}

Most adjuvant chemotherapy trials were performed in unselected patient populations or, more precisely, in populations selected according exclusively to anatomy (axillary status) or demographics (menopausal status) rather than tumor biology. Most of these trials did not stratify patients according to hormonal status, even though the relevance of this biologic factor was well known at the time when the trials were designed. This lack of forward thinking is unfortunate. We know that, overall, the taxane containing combinations are superior to anthracycline (nontaxane) containing combinations, and that the anthracyclines performed better than CMF. In general, however, this superiority is associated with more toxicity. Furthermore, the benefit of the newer combinations over the older ones is small (3\% to $5 \%$ in absolute terms), and we cannot identify the subsets of patients who actually benefit from the new drugs. In other words, we need to treat 100 patients to benefit only three to five of them, while administering what is usually a more toxic treatment to the remaining 95 to 98 patients who do not derive any survival benefit.

Several attempts have been made to identify the population that actually benefits from anthracyclines versus CMF and taxanes versus anthracyclines, but all of them are based on retrospective subset analyses and meta-analyses.

Anthracyclines were considered the gold standard of adjuvant chemotherapy until the late 1990s. In absolute terms, the absolute DFS benefit conferred by anthracyclines compared with CMF is about $3 \%$ at 5 years and $4 \%$ at 10 years in metaanalyses $[8,9]$, although one can speculate that the benefit with anthracyclines is underestimated by the meta-analyses because of the inclusion of 'unfair' trials with asymmetric design (in particular, two large NSABP trials in which six cycles of CMF were compared with four cycles of $A C$, which identified no differences in outcome). However, the long-term, sometimes fatal side effects of anthracyclines, in particular cardiac toxicity and leukemias/myelodysplastic syndrome, can partly counter-balance these benefits. Anthracyclines can trigger a chronic, usually irreversible, dose-dependent cardiomyopathy (type I) by causing myocardial structural changes and cardiac tissue remodeling, the consequences of which may appear months or years after chemotherapy. Although a well recognized phenomenon, the real magnitude of the problem of severe anthracycline-induced cardiac toxicity is still a matter of debate. In randomized phase III clinical trials, the prevalence of grade 2 to 4 cardiac toxicity with anthracyclines was in the range $0.5 \%$ to $1.5 \%$, although the follow up of these trials was less than 6 years. In the long term, anthracycline-induced cardiac damage could have relevant consequences, according to two population-based studies conducted in older patients [51,52]. The cardiac toxicity of anthracyclines is increased when these drugs are followed by trastuzumab. In the trastuzumab adjuvant trials, the incidence of severe cardiac toxicity with anthracyclines followed by trastuzumab ranged from around $2 \%$ to $4 \%$ [53,54]. Apart from cardiotoxicity, anthracyclines have other important longterm adverse effects, such as acute myeloid leukemia and myelodysplastic syndrome, which occur in around $0.5 \%$ of patients $[55,56]$.

Anthracycline use can be optimized in two ways: by selecting patients who are more likely to benefit from these drugs according to tumor biology, and by reducing the risk for irreversible side effects. The latter could be attempted by diminishing the total cumulative dose, selecting patients at very low cardiac risk (young women without cardiac risks), or introducing the newer liposomal formulations, which are clearly less cardiotoxic.

The selection of patients whose tumors are more likely to respond to anthracyclines is a field of currently intense investigation. Several retrospective analysis and a metaanalysis [57-59] have suggested that the improvement in DFS and OS with adjuvant anthracyclines over CMF in the phase III trials is restricted to patients whose tumors present with the HER2 alteration. Other similar studies, however, have found that the patients who actually benefit from adjuvant anthracyclines are those whose tumors have topoisomerase II $\alpha$ amplification [58,60]. A plausible explanation for this discrepancy is that most if not all topoisomerase II $\alpha$ amplifications are observed in tumors with concurrent HER2 amplification [54]. Therefore, topoisomerase II $\alpha$ amplification and not HER2 amplification would be the real predictive factor. Regardless, the demonstration that the adjuvant administration of the new targeted anti-HER2 monoclonal antibody trastuzumab significantly improves DFS and OS in breast cancer patients whose tumors over-express HER2 [54,61-64] will probably change the role of anthracyclines in the adjuvant setting.

Anthracyclines appear to be most effective in patients whose tumors have topoisomerase II $\alpha$ amplification (usually associated with HER2 amplification), and we now have newer, less toxic drugs that effectively target HER2-amplified tumors; the role of anthracyclines should therefore be revisited. Interestingly, support for this idea comes from the BCIRG 006 trial [54], which compared AC followed by docetaxel versus this same regimen plus trastuzumab and the nonanthracycline-containing combination THC (docetaxel, carboplatin, and trastuzumab) as adjuvant therapy for operable 


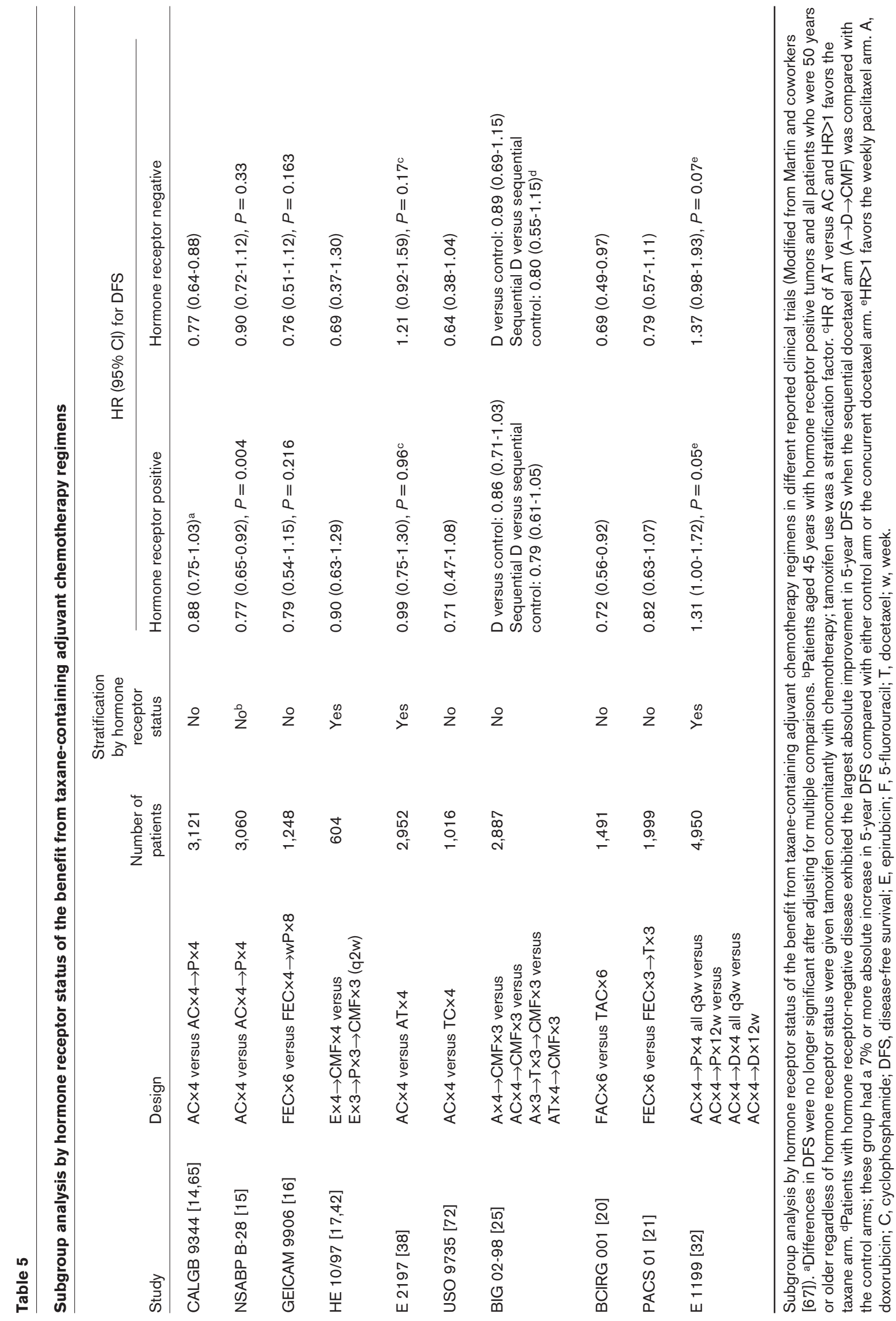


breast tumors over-expressing HER2. A subgroup analysis showed that $A C$ followed by docetaxel plus trastuzumab was not superior to THC in either subgroup of patients (topoisomerase II $\alpha$ amplified and nonamplified tumors). Statistically significant superiority of the two trastuzumabcontaining arms over AC followed by docetaxel was observed in the group of patients whose tumors had amplification of HER2 but not of topoisomerase II $\alpha$. In the subgroup of patients whose tumors had co-amplification of both genes, the three arms were similarly effective. If these data are maintained over time, then the role of anthracyclines in the adjuvant setting would be seriously challenged, because THC could be concluded to be similarly effective and is clearly less cardiotoxic than the anthracycline-containing combinations.

Regarding the taxanes, several attempts have been made to discover molecular factors that could predict response to these drugs. Unfortunately, none of the first-generation adjuvant taxane trials were designed to determine the effectiveness of taxanes in subgroups of patients with different tumor biomarkers, with only retrospective, unplanned analyses being available.

Berry and coworkers [65] reported the results of a combined analysis of the CALGB/Intergroup experience, suggesting that the benefit in favor of the most active chemotherapy regimens, in particular those containing paclitaxel, over the less aggressive ones is mostly limited to patients with ERnegative breast cancer. Conversely, the pooled analysis of BCIRG 001 and PACS-01 reported by Andre and coworkers [66] did not identify any different effect on risk for recurrence or death in ER-positive or ER-negative patients treated with adjuvant docetaxel. The discrepancy in results of the same subset analysis is also present in two trials with very similar design (CALGB-9344 [14] and NSABP B-28 [15]), which compared $A C$ versus $A C$ followed by paclitaxel, and this clearly highlights the caution we should exercise when looking at the results of unplanned subset analyses. Furthermore, the results of other trials such as GEICAM 9906 [16] do not support Berry's suggestion. A specific review [67] and the taxane meta-analysis data do not support the view that the efficacy of taxanes is significantly related to hormone receptor status. In particular, De Laurentiis and coworkers [42] were able to show that taxanes significantly reduced the risk for recurrence, irrespective of ER status (ER positive: $\mathrm{HR}=0.83$, $P<0.00001$; and ER negative: $\mathrm{HR}=0.79, P<0.00001)$, and that the magnitude of the relative benefit was almost constant across subgroups (Table 5).

The relationship between HER2 status and taxane efficacy has been explored in a few studies, which yielded conflicting conclusions. Hayes and coworkers, using tumor samples from patients of the CALBG-9344 trial [68], tried to determine whether HER2 expression identified patients who were likely to benefit from doses of doxorubicin above

\section{This article is part of a review series on \\ Recent advances in systemic therapy, edited by Paul Ellis.}

Other articles in the series can be found online at http://breast-cancer-research.com/series/ bcr_systemic therapy

$60 \mathrm{mg} / \mathrm{m}^{2}$, the addition of paclitaxel after anthracyclines, or both. There was an interaction between HER2 positivity and benefit from paclitaxel addition, with an HR for recurrence of $0.59(P=0.01)$ regardless of ER status. However, these results were not confirmed by the GEICAM 9906 trial [16], in which no significant interaction was found between treatment with paclitaxel and HER2 status.

Other molecular markers that are more or less related to the mechanism of action or metabolism of taxanes (such as $\beta$-tubulin isotypes, protein tau, P-glycoprotein, and so on) and some genetic signatures have been proposed as predictors of taxane efficacy $[69,70]$. These studies have a reduced power to detect clinically meaningful relationship because of the limited sample size and other methodological problems. None of these markers have been validated by large prospective clinical trials or meta-analysis, and therefore we are presently unable to select patients who may benefit from adjuvant taxanes based on molecular features.

\section{Conclusions}

Taxanes and trastuzumab have permanently entered the adjuvant setting, based on their consistently positive results in randomized clinical trials. The discussion of which is the best regimen or schedule, and new strategies to combine all of these tools is wide open. However, these new alternatives have challenged the established role of anthracyclines as the backbone of adjuvant treatment in early breast cancer. With a growing pool of active drugs, their tolerability and - more importantly - their long-term toxicity profiles come into focus when considerations turn to cure and preservation of quality of life.

A whole spectrum of targeted drugs is being or is about to be tested for use in early breast cancer, once they have demonstrated activity in advanced stages of the disease. Their ability to interfere with survival, proliferation, and angiogenesis or the motility, migration, and invasiveness processes of tumor cells could be even more relevant in this earlier phase of the natural history of breast cancer.

As the number of treatment options increases, the need to define a set of criteria to select those patients who will benefit from each treatment regimen or strategy becomes a priority. The appropriateness of clinical trial designs to address this issue is currently a major concern. 


\section{Competing interests}

The authors declare that they have no competing interests.

\section{References}

1. Valagussa $\mathrm{P}$, Bonadonna G, Veronesi U: Patterns of relapse and survival following radical mastectomy. Analysis of 716 consecutive patients. Cancer 1978, 41:1170-1178.

2. Berry DA, Cronin KA, Plevritis SK, Fryback DG, Clarke L, Zelen M, Mandelblatt JS, Yakovlev AY, Habbema JD, Feuer EJ: Effect of screening and adjuvant therapy on mortality from breast cancer. N Engl J Med 2005, 353:1784-1792.

3. Fisher B, Ravdin RG, Ausman RK, Slack NH, Moore GE, Noer RJ: Surgical adjuvant chemotherapy in cancer of the breast: results of a decade of cooperative investigation. Ann Surg 1968, 168:337-356.

4. Bonadonna G, Brusamolino $E$, Valagussa $P$, Rossi $A$, Brugnatelli L, Brambilla C, De Lena M, Tancini G, Bajetta E, Musumeci R, Veronesi U: Combination chemotherapy as an adjuvant treatment in operable breast cancer. N Engl J Med 1976, 294:405410.

5. Fisher B, Carbone P, Economou SG, Frelick R, Glass A, Lerner H, Redmond C, Zelen M, Band P, Katrych DL, Wolmark N, Fisher ER: 1-Phenylalanine mustard (L-PAM) in the management of primary breast cancer. A report of early findings. N Engl J Med 1975, 292:117-122.

6. Bonadonna G, Valagussa $\mathrm{P}$, Moliterni A, Zambetti M, Brambilla C: Adjuvant cyclophosphamide, methotrexate, and fluorouracil in node-positive breast cancer: the results of $\mathbf{2 0}$ years of followup. N Engl J Med 1995, 332:901-906.

7. Early Breast Cancer Trialists' Collaborative Group: Polychemotherapy for early breast cancer: an overview of the randomised trials. Lancet 1998, 352:930-942.

8. Early Breast Cancer Trialists' Collaborative Group Effects of chemotherapy and hormonal therapy for early breast cancer on recurrence and 15-year survival: an overview of the randomised trials. Lancet 2005, 365:1687-1717.

9. Peto R: The worldwide overview: new results for systemic adjuvant therapies. Plenary Lecture. In 30th Annual San Antonio Breast Cancer Symposium. San Antonio, TX; 2007.

10. Fisher B, Anderson S, Tan-Chiu E, Wolmark N, Wickerham DL, Fisher ER, Dimitrov NV, Atkins JN, Abramson N, Merajver S, Romond EH, Kardinal CG, Shibata HR, Margolese RG, Farrar WB: Tamoxifen and chemotherapy for axillary node-negative, estrogen receptor-negative breast cancer: findings from National Surgical Adjuvant Breast and Bowel Project B-23. J Clin Oncol 2001, 19:931-942.

11. Fisher B, Brown AM, Dimitrov NV, Poisson R, Redmond C, Margolese RG, Bowman D, Wolmark N, Wickerham DL, Kardinal CG, et al: Two months of doxorubicin-cyclophosphamide with and without interval reinduction therapy compared with 6 months of cyclophosphamide, methotrexate, and fluorouracil in positive-node breast cancer patients with tamoxifen-nonresponsive tumors: results from the National Surgical Adjuvant Breast and Bowel Project B-15. J Clin Oncol 1990, 8:14831496.

12. Martin M, Villar A, Sole-Calvo A, Gonzalez R, Massuti B, Lizon J, Camps C, Carrato A, Casado A, Candel MT, Albanell J, Aranda J, Munarriz B, Campbell J, Diaz-Rubio E; GEICAM Group (Spanish Breast Cancer Research Group), Spain: Doxorubicin in combination with fluorouracil and cyclophosphamide (i.v. FAC regimen, day 1,21 ) versus methotrexate in combination with fluorouracil and cyclophosphamide (i.v. CMF regimen, day 1, 21) as adjuvant chemotherapy for operable breast cancer: a study by the GEICAM group. Ann Oncol 2003, 14:833-842.

13. Fumoleau $P$, Kerbrat $P$, Romestaing $P$, Fargeot $P$, Bremond $A$, Namer M, Schraub S, Goudier MJ, Mihura J, Monnier A, Clavère P, Serin D, Seffert P, Pourny C, Facchini T, Jacquin JP, Sztermer JF, Datchary J, Ramos R, Luporsi E: Randomized trial comparing six versus three cycles of epirubicin-based adjuvant chemotherapy in premenopausal, node-positive breast cancer patients: 10-year follow-up results of the French Adjuvant Study Group 01 trial. J Clin Oncol 2003, 21:298-305.

14. Henderson IC, Berry DA, Demetri GD, Cirrincione CT, Goldstein LJ, Martino S, Ingle JN, Cooper MR, Hayes DF, Tkaczuk KH, Fleming G, Holland JF, Duggan DB, Carpenter JT, Frei E 3rd, Schilsky RL, Wood WC, Muss HB, Norton L: Improved out- comes from adding sequential paclitaxel but not from escalating doxorubicin dose in an adjuvant chemotherapy regimen for patients with node-positive primary breast cancer. J Clin Oncol 2003, 21:976-983.

15. Mamounas EP, Bryant J, Lembersky B, Fehrenbacher L, Sedlacek SM, Fisher B, Wickerham DL, Yothers G, Soran A, Wolmark N: Paclitaxel after doxorubicin plus cyclophosphamide as adjuvant chemotherapy for node-positive breast cancer: results from NSABP B-28. J Clin Oncol 2005, 23:3686-3696.

16. Martin M, Rodriguez-Lescure A, Ruiz A, Alba E, Calvo L, RuizBorrego M, Munarriz B, Rodriguez CA, Crespo C, de Alava E, López García-Asenjo JA, Guitián MD, Almenar S, González-Palacios JF, Vera F, Palacios J, Ramos M, Gracia Marco JM, Lluch A, Alvarez I, Seguí MA, Mayordomo Jl, Antón A, Baena JM, Plazaola A, Modolell A, Pelegrí A, Mel JR, Aranda E, Adrover E, et al.: Randomized phase 3 trial of fluorouracil, epirubicin, and cyclophosphamide alone or followed by Paclitaxel for early breast cancer. J Nat/ Cancer Inst 2008, 100:805-814.

17. Fountzilas G, Skarlos D, Dafni U, Gogas H, Briasoulis E, Pectasides D, Papadimitriou C, Markopoulos C, Polychronis A, Kalofonos HP, Siafaka V, Kosmidis P, Timotheadou E, Tsavdaridis D, Bafaloukos D, Papakostas P, Razis E, Makrantonakis P, Aravantinos G, Christodoulou C, Dimopoulos AM: Postoperative dosedense sequential chemotherapy with epirubicin, followed by CMF with or without paclitaxel, in patients with high-risk operable breast cancer: a randomized phase III study conducted by the Hellenic Cooperative Oncology Group. Ann Oncol 2005, 16:1762-1771.

18. Burnell $M$, Levine $M$, Chapman J: A phase III adjuvant trial of sequenced EC + filgrastim + epoetin-alpha followed by paclitaxel compared to sequenced AC followed by paclitaxel compared to CEF in women with node-positive or high-risk node-negative breast cancer (NCIC CTG MA.21) [abstract]. J Clin Oncol 2007, 25(suppl):550.

19. Del Mastro L, Costantini M, Durando A, Michelotti A, Danese S, Aitini E, Olmeo N, Pronzato P, Venturini M: Cyclophosphamide, epirubicin, and 5-fluorouracil versus epirubicin plus paclitaxel in node-positive early breast cancer patients: a randomized, phase III study of Gruppo Oncologico Nord Ovest-Mammella Intergruppo Group [abstract]. J Clin Oncol 2008, 26(suppl): 516.

20. Martin M, Pienkowski T, Mackey J, Pawlicki M, Guastalla JP, Weaver C, Tomiak E, Al-Tweigeri T, Chap L, Juhos E, Guevin R, Howell A, Fornander T, Hainsworth J, Coleman R, Vinholes J, Modiano M, Pinter T, Tang SC, Colwell B, Prady C, Provencher L, Walde D, Rodriguez-Lescure A, Hugh J, Loret C, Rupin M, Blitz S, Jacobs $\mathrm{P}$, Murawsky M: Adjuvant docetaxel for node-positive breast cancer. N Engl J Med 2005, 352:2302-2313.

21. Roche H, Fumoleau P, Spielmann M, Canon JL, Delozier T, Serin $D$, Symann M, Kerbrat $P$, Soulie $P$, Eichler F, Viens $P$, Monnier A, Vindevoghel A, Campone M, Goudier MJ, Bonneterre J, Ferrero JM, Martin AL, Genève J, Asselain B: Sequential adjuvant epirubicin-based and docetaxel chemotherapy for node-positive breast cancer patients: the FNCLCC PACS 01 Trial. J Clin Oncol 2006, 24:5664-5671.

22. Goldstein LJ, O'Neill A, Sparano JA, Perez EA, Shulman LN, Martino S, Davidson NE: Concurrent doxorubicin plus docetaxel is not more effective than concurrent doxorubicin plus cyclophosphamide in operable breast cancer with 0 to 3 positive axillary nodes: North American Breast Cancer Intergroup Trial E 2197. J Clin Oncol 2008, 26:4078-4085.

23. Jones SE, Savin MA, Holmes FA, O'Shaughnessy JA, Blum JL, Vukelja S, Mclntyre KJ, Pippen JE, Bordelon JH, Kirby R, Sandbach J, Hyman WJ, Khandelwal $P$, Negron AG, Richards DA, Anthony SP, Mennel RG, Boehm KA, Meyer WG, Asmar L: Phase III trial comparing doxorubicin plus cyclophosphamide with docetaxel plus cyclophosphamide as adjuvant therapy for operable breast cancer. J Clin Oncol 2006, 24:5381-5387.

24. Jones S, Holmes FA, O'Shaughnessy J, Blum JL, Vukelja SJ, Mclntyre KJ, Pippen JE, Bordelon JH, Kirby RL, Sandbach J, Hyman WJ, Richards DA, Mennel RG, Boehm KA, Meyer WG, Asmar L, Mackey $D$, Riedel $S$, Muss $H$, Savin MA: Docetaxel with cyclophosphamide is associated with an overall survival benefit compared with doxorubicin and cyclophosphamide: 7year follow-up of US Oncology Research Trial 9735. J Clin Oncol 2009, 27:1177-1183.

25. Francis $P$, Crown J, Di Leo A, Buyse M, Balil A, Andersson M, Nor- 
denskjold B, Lang I, Jakesz R, Vorobiof D, Gutiérrez J, van Hazel G, Dolci S, Jamin S, Bendahmane B, Gelber RD, Goldhirsch A, Castiglione-Gertsch M, Piccart-Gebhart M; BIG 02-98 Collaborative Group: Adjuvant chemotherapy with sequential or concurrent anthracycline and docetaxel: Breast International Group 02-98 randomized trial. J Natl Cancer Inst 2008, 100:121-133.

26. Bianco A, De Matteis A, Manzione L, Boni C, Palazzo S, Di Palma M, lacono C, De Placido S, Papaldo P, Cognetti F: Taxit216 Study Group. Sequential Epirubicin-Docetaxel-CMF as adjuvant therapy of early breast cancer: results of the Taxit216 multicenter phase III trial. J Clin Oncol 2006, 24:LBA520.

27. Ellis $P$, Barrett-Lee $P$, Bloomfield D, Cameron D, Hall E, Johnson $\mathrm{L}$, Johnston S, Bliss J: Preliminary results of the UK Taxotere as Adjuvant Chemotherapy (TACT) Trial. UK-CRUK trial. In: 30th San Antonio Breast Cancer Symposium: 2007; San Antonio, Texas; 2007: Abstract 78.

28. Martin M, lluch A, Segui M, Ruiz A, Ramos M, Adrover Cebrián E, Rodriguez-Lescure A, Grosse R, Calvo Martínez L, Antón A: Multicenter, randomized phase III study of adjuvant chemotherapy for high-risk, node-negative breast cancer comparing tac with fac: 5-year efficacy analysis of the GEICAM 9805 trial. $J$ Clin Oncol ASCO Annual Meeting Proceedings 2008, 26(S1): Abstract 542

29. Mavroudis D, Malamos NP, P, Adamou A, Christophyllakis C, Ziras N, Syrigos K, Kakolyris S, Kouroussis CG, V: Randomized phase III trial comparing the sequential administration of docetaxel followed by epirubicin plus cyclophosphamide versus FE75C as adjuvant chemotherapy in axillary lymph node positive breast cancer. J Clin Oncol ASCO Annual Meeting Proceedings 2008, 26(S1):Abstract 521

30. Nitz U, Huober J, Lisboa B, Harbeck N, Fischer $H$, Moebus $V$, Hoffmann G, Augustin D, Weiss E: Superiority of sequential docetaxel over standard FE100C in patients with intermediate risk breast cancer: survival results of the randomized intergroup phase III trial EC-Doc [abstract]. In 31st Annual San Antonio Breast Cancer Symposium: 2008. San Antonio, TX; 2008.78.

31. Citron ML, Berry DA, Cirrincione C, Hudis C, Winer EP, Gradishar WJ, Davidson NE, Martino S, Livingston R, Ingle JN, Perez EA, Carpenter J, Hurd D, Holland JF, Smith BL, Sartor Cl, Leung EH, Abrams J, Schilsky RL, Muss HB, Norton L: Randomized trial of dose-dense versus conventionally scheduled and sequential versus concurrent combination chemotherapy as postoperative adjuvant treatment of node-positive primary breast cancer: first report of Intergroup Trial C9741/Cancer and Leukemia Group B Trial 9741. J Clin Oncol 2003, 21:14311439.

32. Sparano JA, Wang M, Martino S, Jones V, Perez EA, Saphner T, Wolff AC, Sledge GW, Jr., Wood WC, Davidson NE: Weekly paclitaxel in the adjuvant treatment of breast cancer. $N$ Engl J Med 2008, 358:1663-1671.

33. Poole C, Hiller L, Howard H, Dunn J, Canney P, Wardley A, Kennedy M, Coleman R, Leonard R, Earl H: tAnGo trial collaborators. tAnGo: a randomized phase III trial of gemcitabine (gem) in paclitaxel-containing, epirubicin/cyclophosphamidebased, adjuvant chemotherapy (CT) for women with earlystage breast cancer (EBC) [abstract]. J Clin Oncol 2008, 26 (suppl):506.

34. Swain SM, Jeong J-H, Geyer CE, Costantino JP, Pajon ER, Fehrenbacher L, Atkins JN, Polikoff J, Vogel VG, Erban JK, Livingston RB, Perez EA, Mamounas EP, Ganz PA, Land SR, Wolmark N: NSABP B-30: definitive analysis of patient outcome from a randomized trial evaluating different schedules and combinations of adjuvant therapy containing doxorubicin, docetaxel and cyclophosphamide in women with operable, node-positive breast cancer [abstract]. In 31st Annual San Antonio Breast Cancer Symposium: 2008. San Antonio, TX; 2008:75.

35. Eiermann W, Pienkowski T, Crown J, Chap L, Pawlicki M, Martin M, Saleh M, Sehdev S, Provencher L, Von Minckwitz G, Semiglazov V, Slamon D, Tabah-Fisch I, Buyse M, Riva A, Taupin H, Sauter G, Mackey J: BCIRG 005 main efficacy analysis: a phase III randomized trial comparing docetaxel in combination with doxorubicin and cyclophosphamide (TAC) versus doxorubicin and cyclophosphamide followed by docetaxel $(A C->T)$ in women with Her-2/neu negative axillary lymph node positive early breast cancer [abstract]. In 31 st Annual
San Antonio Breast Cancer Symposium: 2008. San Antonio, TX; 2008:77.

36. Buzdar AU, Singletary SE, Valero V, Booser DJ, Ibrahim NK, Rahman Z, Theriault RL, Walters R, Rivera E, Smith TL, Holmes FA, Hoy E, Frye DK, Manuel N, Kau SW, McNeese MD, Strom E, Thomas E, Hunt K, Ames F, Berry D, Hortobagyi GN: Evaluation of paclitaxel in adjuvant chemotherapy for patients with operable breast cancer: preliminary data of a prospective randomized trial. Clin Cancer Res 2002, 8:1073-1079.

37. Gianni L, Baselga J, Eiermann W, Guillem Porta V, Semiglazov V, Lluch A, Zambetti M, Valagussa PB, G: European Cooperative Trial in Operable Breast Cancer (ECTO): Improved freedom from progression (FFP) from adding paclitaxel (T) to doxorubicin (A) followed by cyclophosphamide methotrexate and fluorouracil (CMF) [abstract]. J Clin Oncol 2005, 23(suppl): 513.

38. Goldstein L, O'Neill A, Sparano J: E2197: Phase III of AT vs AC in the adjuvant treatment of node-positive and high-risk node-negative breast cancer [abstract]. J Clin Oncol 2005, 24: 512.

39. Bria E, Nistico C, Cuppone F, Carlini P, Ciccarese M, Milella M, Natoli G, Terzoli E, Cognetti F, Giannarelli D: Benefit of taxanes as adjuvant chemotherapy for early breast cancer: pooled analysis of 15,500 patients. Cancer 2006, 106:2337-2344.

40. Ferguson T, Wilcken N, Vagg R, Ghersi D, Nowak AK: Taxanes for adjuvant treatment of early breast cancer. Cochrane Database Syst Rev 2007, 4:CD004421.

41. Joensuu $\mathrm{H}$, Kellokumpu-Lehtinen $\mathrm{PL}$, Bono $\mathrm{P}$, Alanko $\mathrm{T}$, Kataja $\mathrm{V}$, Asola R, Utriainen T, Kokko R, Hemminki A, Tarkkanen M, Turpeenniemi-Hujanen T, Jyrkkiö S, Flander M, Helle L, Ingalsuo S, Johansson K, Jääskeläinen AS, Pajunen $M$, Rauhala $M$, KalevaKerola J, Salminen T, Leinonen M, Elomaa I, Isola J; FinHer Study Investigators: Adjuvant docetaxel or vinorelbine with or without trastuzumab for breast cancer. N Engl J Med 2006, 354:809820.

42. De Laurentiis M, Cancello G, D'Agostino D, Giuliano M, Giordano A, Montagna E, Lauria R, Forestieri V, Esposito A, Silvestro L, Pennacchio R, Criscitiello C, Montanino A, Limite G, Bianco AR, De Placido S: Taxane-based combinations as adjuvant chemotherapy of early breast cancer: a meta-analysis of randomized trials. J Clin Oncol 2008, 26:44-53.

43. Bear HD, Anderson S, Smith RE, Geyer CE, Mamounas EP, Fisher B, Brown AM, Robidoux A, Margolese R, Kahlenberg MS, Paik S, Soran A, Wickerham DL, Wolmark N: Sequential preoperative or postoperative docetaxel added to preoperative doxorubicin plus cyclophosphamide for operable breast cancer:National Surgical Adjuvant Breast and Bowel Project Protocol B-27. J Clin Oncol 2006, 24:2019-2027.

44. Evans TR, Yellowlees A, Foster E, Earl H, Cameron DA, Hutcheon AW, Coleman RE, Perren T, Gallagher CJ, Quigley M, Crown J, Jones AL, Highley M, Leonard RC, Mansi JL: Phase III randomized trial of doxorubicin and docetaxel versus doxorubicin and cyclophosphamide as primary medical therapy in women with breast cancer: an anglo-celtic cooperative oncology group study. J Clin Oncol 2005, 23:2988-2995.

45. Henry NL, Hayes DF: Can biology trump anatomy? Do all nodepositive patients with breast cancer need chemotherapy? J Clin Oncol 2007, 25:2501-2503.

46. Anjuvant! Online [www.adjuvantonline.com].

47. Olivotto IA, Bajdik CD, Ravdin PM, Speers $\mathrm{CH}$, Coldman AJ, Norris BD, Davis GJ, Chia SK, Gelmon KA: Population-based validation of the prognostic model ADJUVANT! for early breast cancer. J Clin Oncol 2005, 23:2716-2725.

48. Goldhirsch A, Wood WC, Gelber RD, Coates AS, Thurlimann B Senn HJ: Progress and promise: highlights of the international expert consensus on the primary therapy of early breast cancer 2007. Ann Oncol 2007, 18:1133-1144.

49. Cardoso F, Van't Veer L, Rutgers E, Loi S, Mook S, PiccartGebhart MJ: Clinical application of the 70 -gene profile: the MINDACT trial. J Clin Oncol 2008, 26:729-735.

50. Sparano JA, Paik S: Development of the 21-gene assay and its application in clinical practice and clinical trials. J Clin Oncol 2008, 26:721-728.

51. Doyle JJ, Neugut Al, Jacobson JS, Grann VR, Hershman DL: Chemotherapy and cardiotoxicity in older breast cancer patients: a population-based study. J Clin Oncol 2005, 23: 8597-8605. 
52. Pinder MC, Duan Z, Goodwin JS, Hortobagyi GN, Giordano SH: Congestive heart failure in older women treated with adjuvant anthracycline chemotherapy for breast cancer. J Clin Oncol 2007, 25:3808-3815.

53. Perez EA, Suman VJ, Davidson NE, Sledge GW, Kaufman PA, Hudis CA, Martino S, Gralow JR, Dakhil SR, Ingle JN, Winer EP, Gelmon KA, Gersh BJ, Jaffe AS, Rodeheffer RJ: Cardiac safety analysis of doxorubicin and cyclophosphamide followed by paclitaxel with or without trastuzumab in the North Central Cancer Treatment Group N9831 adjuvant breast cancer trial. J Clin Oncol 2008, 26:1231-1238.

54. Slamon D, Eiermann W, Robert N, Pienkowski T, Martin M, Pawlicki M, Chan A, Smylie M, Liu M, Falkson C, Pinter T, Fornander T, Shiftan T, Valero V, Mackey J, Tabah-Fisch I, Buyse M, Lindsay M, Riva A, Bee V, Pegram M, Press M, Crown J: BCIRG 006: 2nd interim analysis phase III randomized trial comparing doxorubicin and cyclophosphamide followed by docetaxel (AC T) with doxorubicin and cyclophosphamide followed by docetaxel and trastuzumab (AC TH) with docetaxel, carboplatin and trastuzumab (TCH) in Her2neu positive early breast cancer patients [abstract]. Breast Cancer Res Treat 2006, 100(Suppl 1):52.

55. Praga C, Bergh J, Bliss J, Bonneterre J, Cesana B, Coombes RC, Fargeot $\mathrm{P}$, Folin A, Fumoleau $\mathrm{P}$, Giuliani R, Kerbrat $\mathrm{P}$, Hery M, Nilsson J, Onida F, Piccart M, Shepherd L, Therasse P, Wils J, Rogers D: Risk of acute myeloid leukemia and myelodysplastic syndrome in trials of adjuvant epirubicin for early breast cancer: correlation with doses of epirubicin and cyclophosphamide. J Clin Oncol 2005, 23:4179-4191.

56. Smith RE, Bryant J, DeCillis A, Anderson S: Acute myeloid leukemia and myelodysplastic syndrome after doxorubicincyclophosphamide adjuvant therapy for operable breast cancer: the National Surgical Adjuvant Breast and Bowel Project Experience. J Clin Oncol 2003, 21:1195-1204.

57. Gennari A, Sormani MP, Pronzato P, Puntoni M, Colozza M, Pfeffer U, Bruzzi P: HER2 status and efficacy of adjuvant anthracyclines in early breast cancer: a pooled analysis of randomized trials. J Natl Cancer Inst 2008, 100:14-20.

58. Knoop AS, Knudsen H, Balslev E, Rasmussen BB, Overgaard J, Nielsen KV, Schonau A, Gunnarsdottir K, Olsen KE, Mouridsen H, Ejlertsen B; Danish Breast Cancer Cooperative Group: retrospective analysis of topoisomerase lla amplifications and deletions as predictive markers in primary breast cancer patients randomly assigned to cyclophosphamide, methotrexate, and fluorouracil or cyclophosphamide, epirubicin, and fluorouracil: Danish Breast Cancer Cooperative Group. J Clin Oncol 2005, 23:7483-7490.

59. Pritchard KI, Shepherd LE, O'Malley FP, Andrulis IL, Tu D, Bramwell VH, Levine MN: HER2 and responsiveness of breast cancer to adjuvant chemotherapy. N Engl J Med 2006, 354: 2103-2111.

60. Tanner M, Isola J, Wiklund T, Erikstein B, Kellokumpu-Lehtinen $\mathrm{P}$, Malmstrom P, Wilking N, Nilsson J, Bergh J: Topoisomerase Ilalpha gene amplification predicts favorable treatment response to tailored and dose-escalated anthracycline-based adjuvant chemotherapy in HER-2/neu-amplified breast cancer: Scandinavian Breast Group Trial 9401. J Clin Oncol 2006, 24:2428-2436.

61. Perez E, Romond E, Suman V, Jeong J, Davidson N, Geyer C, Martino SM, EP, Kauffman P, Wolmark N: Updated results of the combined analysis of NCCTG N9831 and NSABP B-31 adjuvant chemotherapy with/without trastuzumab in patiens with HER2-positive breast cancer [abstract]. J Clin Oncol 2007, 25 (suppl):512.

62. Piccart-Gebhart MJ, Procter M, Leyland-Jones B, Goldhirsch A, Untch M, Smith I, Gianni L, Baselga J, Bell R, Jackisch C, Cameron D, Dowsett M, Barrios CH, Steger G, Huang CS, Andersson $M$, Inbar $M$, Lichinitser $M$, Láng I, Nitz $U$, Iwata $H$, Thomssen C, Lohrisch C, Suter TM, Rüschoff J, Suto T, Greatorex V, Ward C, Straehle C, McFadden E: Trastuzumab after adjuvant chemotherapy in HER2-positive breast cancer. $N$ Engl J Med 2005, 353:1659-1672.

63. Romond EH, Perez EA, Bryant J, Suman VJ, Geyer CE Jr, Davidson NE, Tan-Chiu E, Martino S, Paik S, Kaufman PA, Swain SM, Pisansky TM, Fehrenbacher L, Kutteh LA, Vogel VG, Visscher DW, Yothers G, Jenkins RB, Brown AM, Dakhil SR, Mamounas EP, Lingle WL, Klein PM, Ingle JN, Wolmark N: Trastuzumab plus adjuvant chemotherapy for operable HER2-positive breast cancer. N Engl J Med 2005, 353:1673-1684.

64. Smith I, Procter M, Gelber RD, Guillaume S, Feyereislova A Dowsett M, Goldhirsch A, Untch M, Mariani G, Baselga J, Kaufmann M, Cameron D, Bell R, Bergh J, Coleman R, Wardley A, Harbeck N, Lopez RI, Mallmann P, Gelmon K, Wilcken N, Wist E, Sánchez Rovira P, Piccart-Gebhart MJ; HERA study tea: 2-year follow-up of trastuzumab after adjuvant chemotherapy in HER2-positive breast cancer: a randomised controlled trial. Lancet 2007, 369:29-36.

65. Berry DA, Cirrincione C, Henderson IC, Citron ML, Budman DR, Goldstein LJ, Martino S, Perez EA, Muss HB, Norton L, Hudis C, Winer EP: Estrogen-receptor status and outcomes of modern chemotherapy for patients with node-positive breast cancer. JAMA 2006, 295:1658-1667.

66. Andre F, Broglio K, Roche H, Martin M, Mackey JR, Penault-Llorca F, Hortobagyi GN, Pusztai L: Estrogen receptor expression and efficacy of docetaxel-containing adjuvant chemotherapy in patients with node-positive breast cancer: results from a pooled analysis. J Clin Oncol 2008, 26:2636-2643.

67. Martin M, Mackey J, Vogel C: Benefit from adjuvant taxanes and endocrine responsiveness in breast cancer. Breast 2007, 16(suppl 2):S127-S131.

68. Hayes DF, Thor AD, Dressler LG, Weaver D, Edgerton S, Cowan D, Broadwater G, Goldstein $U$, Martino S, Ingle JN, Henderson IC, Norton L, Winer EP, Hudis CA, Ellis MJ, Berry DA; Cancer and Leukemia Group B (CALGB) Investigators: HER2 and response to paclitaxel in node-positive breast cancer. $N$ Engl J Med 2007, 357:1496-1506.

69. Noguchi S: Predictive factors for response to docetaxel in human breast cancers. Cancer Sci 2006, 97:813-820.

70. Pusztai L: Markers predicting clinical benefit in breast cancer from microtubule-targeting agents. Ann Oncol 2007, 18(suppl 12):xii15-xii20

71. Clinical Trials [http://www.cancer.gov/clinicaltrials].

72. Jones S, Holmes F, O'Shaughnessy J, Blum J, Vukelaj S, Mclntyre K, Pippen J, Bordelon J, Kirby R, Sandbach J, Hyman W, Khandelwal P, Negron A, Richards D, Mennel R, Boehm K, Meyer W, Asmar L, Muss H, Savin M: Extended follow-up and analysis by age of the US Oncology Adjuvant trial 9735: docetaxel/ cyclophosphamide is associated with an overall survival benefit compared to doxorubicin/ cyclophosphamide and is well-tolerated in women $\mathbf{6 5}$ or older [abstract]. Breast Cancer Res Treat 2007, 106(Suppl 1):12. 